\title{
INFLUENCE OF THE SOIL FABRIC ON THE MECHANICAL PROPERTIES OF UNSATURATED CLAYS
}

\author{
Nikol Kochmanová A $^{\text {i) }}$ and Hiroyuki TANaKA ${ }^{\text {ii) }}$
}

\begin{abstract}
To determine the properties of bentonite in an unsaturated condition, which is typically used in the initial placement of the clay liners in landfills, the effect of the soil fabric on the mechanical properties of unsaturated compacted Kunigel-V1, a bentonite clay, and NSF Clay, a non-swelling clay, were investigated. Samples were prepared at varying gravimetric water contents, ranging from natural to $70 \%$, with the use of distilled water. The soil fabric was studied using scanning electron microscopy (SEM) and mercury intrusion porosimetry (MIP). The mechanical behaviour was studied by constant rate of strain (CRS) consolidation testing and constant volume direct shear (CVDS) testing. The results indicate that while an increase in water content resulted in the formation of aggregates and an increase in shear strength, it was the dilatancy behaviour that was most affected. The saturation of Kunigel-V1 resulted in a decrease in the friction angle, from $40.4^{\circ}$ to $20.4^{\circ}$, while the saturation of NSF Clay resulted in a decrease in friction angle from over $40^{\circ}$ to $32.3^{\circ}$.
\end{abstract}

Key words: aggregates, constant volume direct shear, dilatancy, mechanical behaviour, microstructure, shear strength, soil fabric, swelling clays (IGC: D3/D5/D6)

\section{INTRODUCTION}

Bentonite, a smectite clay, is widely used in geotechnical engineering as drilling mud, a liner material for municipal solid waste disposal, and it has been proposed as a buffer and backfill material for high-level nuclear waste disposal. In high-level nuclear waste disposal, bentonite is mixed with other materials, such as sand, to create a buffer material surrounding the radioactive waste canisters. Compacted bentonite and bentonite-sand mixtures have been proposed as suitable buffer materials as they provide "low hydraulic conductivity, low ion diffusivity, [and] good self-sealing capacities" (Marcial et al., 2002), while also possessing the ability to adsorb and prevent the migration of radionuclides.

Presently, the majority of studies on the mechanical properties of bentonite have been carried out on fully saturated samples, as it is the desired end condition, such as in the case of nuclear waste disposal where the clay becomes saturated over time. However, bentonite is usually compacted in situ when initially placed or placed as prefabricated as blocks, then compressed by a certain water content to achieve the desired density. Even if placed in powder form, water will eventually be adsorbed by the bentonite, resulting in unsaturated conditions at first, and eventually insaturated conditions given a sufficient amount of time. During the saturation process of the bentonite mixture, the stability of the structure should be examined in the event of changes in the environmental conditions or the occurrence of strong seismic motion. The mechanical behaviour in these unsaturated conditions cannot be explained by either the fully drained or undrained conditions due to the effects of suction and the effects of the diffuse double layer on the clay particles, as will be discussed below. Thus, not only are the properties of clay typically not studied in the unsaturated condition, but also the transitional stages from 'dry' to unsaturated to saturated conditions over time has not been examined.

Despite the aforementioned lack of data on the unsaturated behaviour of clays, the behaviour of partially saturated bentonite has been studied by the geotechnical group at Barcelona University (Alonso et al., 1990; Gens and Alonso, 1992) from the viewpoint of matric suction. However, these studies require long periods of time (in some cases over a year). Additionally, they do not consider the effects of water on the friction angle or the effects of the soil fabric (such as aggregates). The focus of this paper is on the soil fabric formation of bentonite, and its effect on its mechanical properties, namely the compression and shearing behaviour.

\section{EXPERIMENTAL STUDY}

The aim of this ongoing study is to gain an understanding of the effects of the soil fabric on the mechanical

i) Golder Associates Ltd., Hokkaido University PhD graduate (Nikol_Kochmanova@golder.com).

ii) Professor, Hokkaido University, Japan (tanaka@eng.hokudai.ac.jp).

The manuscript for this paper was received for review on November 19, 2010; approved on February 7, 2011.

Written discussions on this paper should be submitted before November 1, 2011 to the Japanese Geotechnical Society, 4-38-2, Sengoku, Bunkyo-ku, Tokyo 112-0011, Japan. Upon request the closing date may be extended one month. 


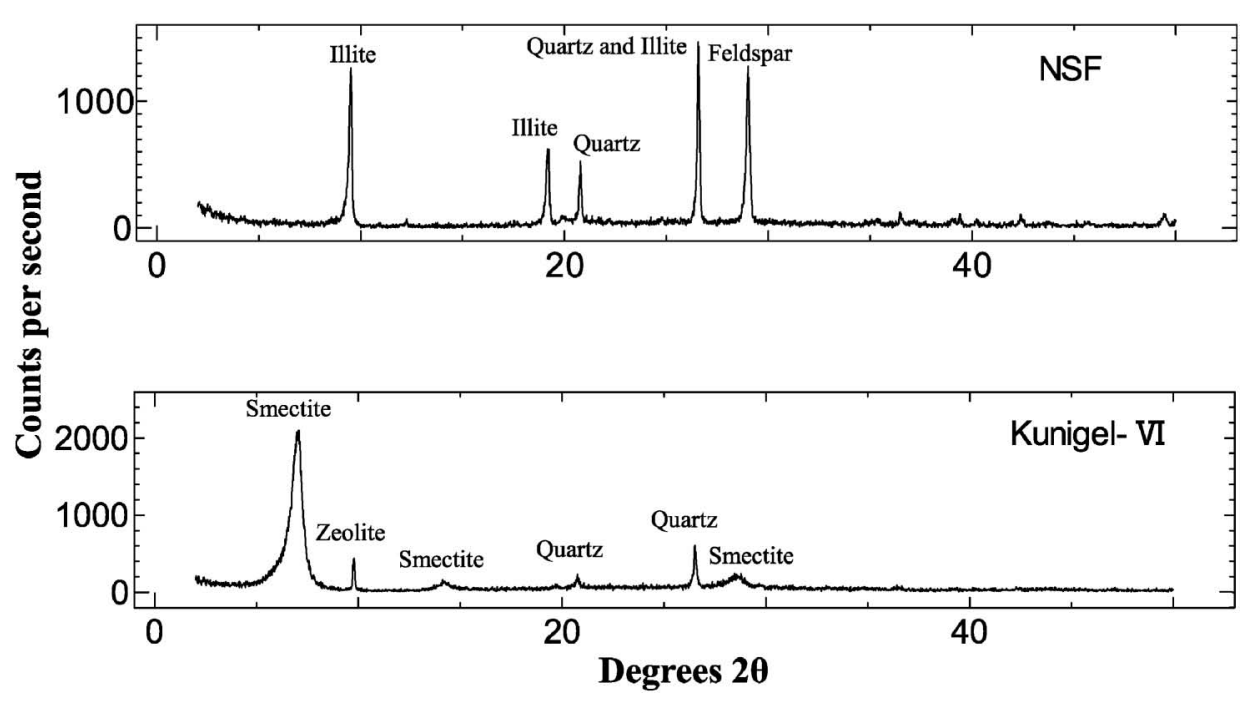

Fig. 1. X-ray diffraction results for NSF Clay and Kunigel-V1

properties of compacted clay, namely Kunigel-V1 and NSF Clay. Scanning Electron Microscopy (SEM) and Mercury Intrusion Porosimetry (MIP) were used to examine the microstructure, while Constant Rate of Strain (CRS) testing and Constant Volume Direct Shear (CVDS) testing were used to examine the mechanical properties. The details of the experimental study are discussed in the next section.

\section{Materials/Specimens}

Two types of clay were used in this study: Kunigel-V1, a swelling clay, and NSF Clay, a non-swelling clay. Kunigel-V1 is a commercial sodium type bentonite from Yamagata, Japan, containing $48 \%$ to $57 \%$ montmorillonite (smectite mineral), with ratios depending on the deposit depth (Komine, 2004; Komine et al., 2009) and other non-swelling minerals, such as quartz, zeolite, and feldspar. NSF Clay is a commercially available non-swelling clay from Okayama, Japan, and is mainly composed of illite, with other minor minerals, such as quartz and feldspar. X-ray diffraction results for oriented clay particles less than $2 \mu \mathrm{m}$ in diameter, shown in Fig. 1, indicate the presence of illite, quartz, and feldspar in NSF Clay but clearly no smectite, whereas the presence of smectite, zeolite, and quartz are indicated in Kunigel-V1. The grain size distribution curves for both clays, shown in Fig. 2, indicate that they have a similar total clay fraction content, with more than $80 \%$ of the particles smaller than 5 $\mu \mathrm{m}$ in both clays. The additional material properties of both clays are presented in Table 1.

For each clay, two types of samples were tested: unsaturated samples and submerged samples. Unsaturated samples were prepared at varying gravimetric water contents, ranging from natural (or dry) samples to those with a water content of $70 \%$. Natural water content samples (dry) refer to samples where no additional water was added to the commercial clays. Distilled water was sprayed onto the soil and mixed to create natural aggregates, resulting in non-homogenous samples. The ob-

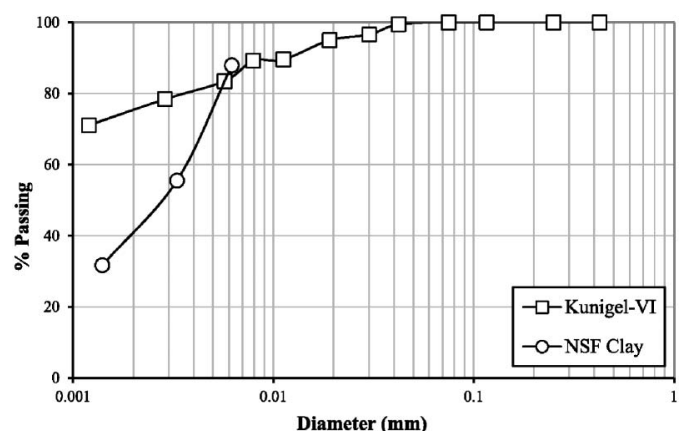

Fig. 2. Particle size analysis for Kunigel-V1 and NSF Clay

Table 1. Material properties

\begin{tabular}{ccc}
\hline Property & Kunigel-V1 & NSF Clay \\
\hline Natural Water Content & $5.0-6.2 \%$ & $0.2-0.5 \%$ \\
Liquid Limit (LL) & $499 \%$ & $55 \%$ \\
Plastic Limit (PL) & $39 \%$ & $29 \%$ \\
\hline
\end{tabular}

jective of using distilled water in this study was to maintain consistent water chemistry conditions. All samples were prepared 24 hours prior to testing to allow for aggregate formation. Kunigel-V1 samples were also tested in submerged conditions, and these samples were prepared in the same manner as described above, but were submerged upon placement in the CRS and CVDS cells (described below).

Samples were prepared at the varying water contents in order to test varying degrees of saturation. For NSF Clay samples, $100 \%$ saturation was reached at the water contents tested, while for Kunigel-V1 100\% saturation was not attained. As numerous studies have been performed on saturated bentonite samples, the authors believed that a closer investigation of bentonite samples at lower saturations was more beneficial. In order to compare the changes in the compression and shearing behavior of the 
samples, both the CRS and CVDS samples were tested at the same water contents for each clay type. The final water contents were decided upon based on an analysis of the CRS results and the microstructure during the beginning stages of this study.

\section{Testing Apparatus and Methodology}

The focus of this study was to examine the effects of the microstructure on the mechanical properties of clays. SEM and MIP were used to examine the clay microstructure, while CRS and CVDS were used to examine the mechanical properties. The details of these apparatuses are discussed below.

(1) Scanning Electron Microscopy (SEM) and Mercury Intrusion Porosimetry (MIP)

SEM and MIP samples were initially compressed using the CRS apparatus, with the sample preparation equivalent to static compaction. Following CRS testing, those samples selected for further testing (SEM and MIP) were wrapped in saran wrap upon extrusion from the loading cell to maintain their water contents. Samples were cut into approximately $10 \mathrm{~mm}$ cubes before being freezedried using liquid nitrogen to maintain the soil structure. The $10 \mathrm{~mm}$ specimens were then placed in a vacuum for 24 hours prior to testing to remove the water.

In SEM, the surface of the soil is scanned using a highenergy beam of electrons which provides an 'image' of the soil, thus allowing a view of the soil's microstructure. Unfortunately, the water within the clay has to be removed, during which time alteration to the microstructure may occur.

In MIP, mercury is inserted into the soil at different pressures using a porosimeter. The pressure at which the mercury is inserted, as well as the volume that enters the soil are both measured and used to determine the pore size distribution of the soil. The pore size distribution of the soil provides a look into formation of the aggregates, thus providing a look into the microstructure of the soil.

(2) Constant Rate of Strain (CRS) Consolidation

CRS testing provides data which indicates the compression behaviour of clay, and the effect of water on its behaviour. Prepared samples with predetermined water contents were placed in an oedometer cell and their height was measured. In some cases, samples were compressed by hand prior to CRS compression, resulting in a lower initial void ratio. The diameter of the oedometer is 60 $\mathrm{mm}$ and the initial height is about $20 \mathrm{~mm}$. Drainage in the upper part of the apparatus was allowed during testing, while the lower part was sealed and used to measure the excess pore water pressure. In conventional CRS testing, the effective consolidation $\left(p^{\prime}\right)$ is calculated by considering the effects of excess pore water pressure $(u)$, such that $p^{\prime}=p-2 / 3 u$, where $p$ is the stress measured by the load cell. Since the samples used in this study are unsaturated, the test results are presented by $p$, not by $p^{\prime}$.

CRS samples were loaded under constant strain ranging from 0.02 to $0.1 \mathrm{~mm}$ per minute, with final pressures ranging from $200 \mathrm{kPa}$ to $15 \mathrm{MPa}$. However, the rate of the strain for the cyclic CRS test was carried out under a constant strain rate of $0.0034 \mathrm{~mm} / \mathrm{min}$ for the virgin loading and the unloading-reloading curves at lower pressures, and $0.00004 \mathrm{~mm} / \mathrm{min}$ for the unloading-reloading curves at higher pressures. The reason for employing these different strain rates will be described below in the results and discussion section.

When the pressure reached a certain value, samples were submerged by introducing water into the cell from the bottom plate of the loading cell, which was connected to the top by an external tube. The water was pushed into the cell using an air pump. Samples were left alone for a period of several weeks until the displacement and pressure became constant.

(3) Constant Volume Direct Shear (CVDS)

In general, the triaxial apparatus is used to measure the strength properties of geotechnical materials, and in the case of fully saturated soils, the drainage condition is controlled by a drainage valve. For unsaturated soils, testing under undrained or constant volume conditions is difficult. Instead, it is reasonable to measure the change in total stresses in addition to the volume change and matric suction; however, special equipment is required for measuring these parameters. Although the fully drained condition is preferable when considering stress conditions, the permeability of bentonite is so small that the strain rate should be small. Additionally, in the fully drained condition, it is possible to measure various parameters critical to unsaturated soils, such as volume change, total stress, and matric suction. Numerous studies have been performed on clays, including bentonite, and these parameters have been characterized. Although the CVDS test cannot measure all of these parameters, it can simulate undrained conditions under constant volume, and thereby determine the role of the soil fabric on the mechanical behaviour of the soil in in-situ conditions, as the number and size of aggregates and voids remain constant. Therefore, it was decided to use the direct shear test apparatus for investigating the shearing properties for unsaturated materials.

The direct shear apparatus used in this study was originally developed by Mikasa (see Takada, 1993). From a comparison study performed by Hanzawa et al. (2007) on Drammen and Ariake clays, it was found that the shearing properties measured by the direct shear apparatus are the same as those measured by the simple shear apparatus at the Norwegian Geotechnical Institute (NGI). In this study, the size and preparation of the specimens are the same as the CRS apparatus, i.e., $60 \mathrm{~mm}$, and with a height of 10 to $20 \mathrm{~mm}$. After applying vertical pressure, constant volume conditions were achieved by fixing the vertical displacement so that any change in the vertical stress can be assumed to correspond to a change in the effective stress in fully saturated samples. Submerged samples were prepared by loading to the appropriate consolidation pressure, after which water was added into the shear box. Samples were left submerged until the normal pressure stabilized. Samples were sheared to a maximum horizontal displacement of $5 \mathrm{~mm}$, corresponding to a cross-sectional area reduction of approximately $10 \%$. 


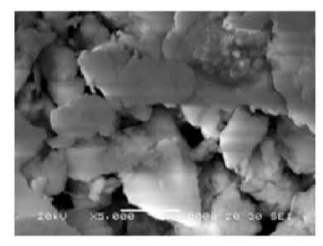

(a)

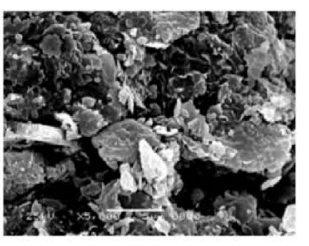

(b)

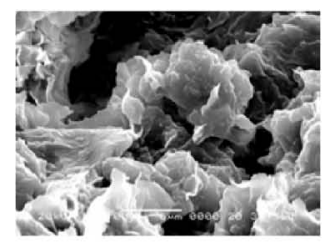

(c)

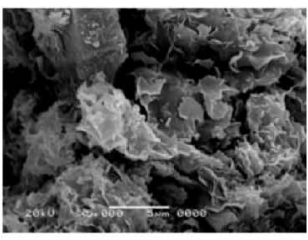

(d)

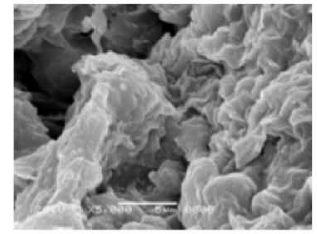

(e)

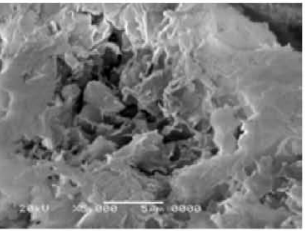

(f)

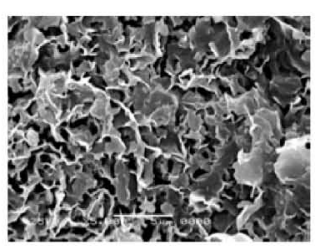

(g)

Fig. 3. SEM results for Kunigel-V1. a) dry, $3 \mathrm{MPa}$, b) dry, $10 \mathrm{MPa}$, c) $30 \%, 0.2 \mathrm{MPa}$, d) $30 \%, 3 \mathrm{MPa}, \mathrm{e}) 50 \%$, $0.2 \mathrm{MPa}$, f) $50 \%, 3 \mathrm{MPa}$, and g) $70 \%, 1.5 \mathrm{MPa}$

\section{RESULTS AND DISCUSSION}

The following describes the results of the testing program. The data discussed here pertains to selected samples from this study. However, extensive testing has been performed on additional samples from which similar results have been obtained.

\section{Microstructure/Soil Fabric Formation}

The soil fabric of both Kunigel-V1 and NSF Clay was examined with the use of SEM and MIP shown in Fig. 3 to Fig. 6. Unfortunately, because wet samples cannot be viewed in SEM, the samples had to be freeze-dried. All SEM images have the same magnification, with the white bar indicating a scale of $5 \mu \mathrm{m}$, with the exception of NSF Clay at a natural water content (Fig. 5(a)) where the white bar indicates a scale of $10 \mu \mathrm{m}$.

(1) Kunigel-V1

The microstructure of Kunigel-V1 can be viewed from the SEM results presented in Fig. 3 and MIP results presented in Fig. 4. At a natural water content, samples are slightly aggregated, as shown by the SEM images in Figs. 3(a) and (b). For SEM results, an aggregate is defined as a group of clay particles, or the bonding between individual particles. Although a small amount of water is present at this point $(5.0 \%-6.2 \%$ as shown in Table 1$)$, the aggregation is mainly due to the mining method of Kunigel-V1, where the clay is obtained from crushed rock.

In dry conditions, the absence of water results in the absence of the diffuse double layer in clays, thus mainly mechanical forces act on the clay particles. The introduction of water results in the formation of the diffuse double layer, resulting in both mechanical and electrostatic forces acting on the particles. When water is introduced to powder clay, the particles are attracted to the water molecules, and due to this strong attraction, the repulsive forces responsible for the interaction of the diffuse double layers between particles are overcome, and bonding

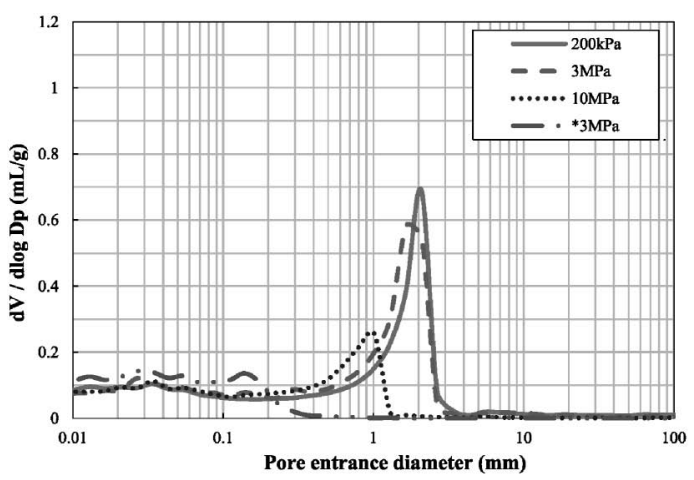

(a)

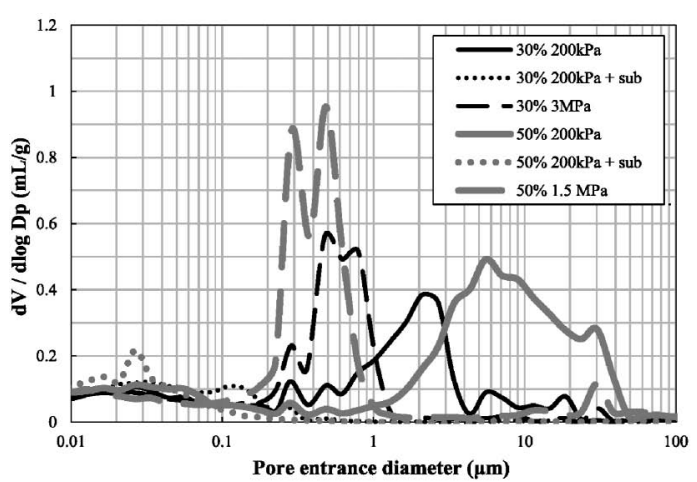

(b)

Fig. 4. MIP results for Kunigel-V1 a) natural water content and b) higher water contents

results in the formation of aggregates. At lower water contents, the formation of aggregates is partly due to the electrostatic forces stated above, but also due to the capillary forces, which attract the particles together. Thus, the addition of water to powder Kunigel-V1 results in the formation of aggregates, causing air and water to become trapped in between the particles; the larger the aggregates, the larger the volume of voids due to the 
presence of both inter and intra aggregate spaces. As more water is added, more particles are bonded together, resulting in an increase in aggregate size due to the increase in aggregation.

In montmorillonite, the water is adsorbed between the particle layers, and the particles expand, causing the attractive forces between the particles to break. The addition of more water, therefore, causes a swelling of the particles, and the creation of larger aggregates. Capillary forces also exist in montmorillonite, but since the water is adsorbed between the particles, the capillary forces are smaller between these particles, though they are larger between smaller-sized aggregates.

The effects of water can be seen by the change in particle alignment and the change in the size and number of voids presented in Figs. 3(c) to (e), which shows samples compressed to $200 \mathrm{kPa}$ at $30 \%$ and $50 \%$ water content, respectively, and from Figs. 3(d) to (f), which shows samples compressed at $3 \mathrm{MPa}$ at $30 \%$ and $50 \%$ water content, respectively. Figure $3(\mathrm{~g})$ shows a sample at $70 \%$ water content, where the particles are bonded in larger aggregates than at lower water contents, as seen by the formation of a honeycomb structure. MIP results show that an increase in water content from a natural water content, shown in Fig. 4(a), to $30 \%$ water content, shown in Fig. 4(b), results in an increase in the volume of voids, shown by an increase in the area under the respective curves. A further increase to 50\% water content, also shown in Fig. 4(b), results in a further increase in the volume of voids. Additionally, at a natural water content and a low pressure of $200 \mathrm{kPa}$, the curve is unimodal, centered around $2 \mu \mathrm{m}$, whereas at water contents of $30 \%$ and $50 \%$ under the same pressure, the curve is spread out over a large range, indicating the existence of both microand macro-voids.

Submergence of the samples caused a further rearrangement of the particles, as they tried to arrange themselves in face-to-face aggregation due to the decrease in strength of the van der Waals forces, resulting in a thin diffuse double layer, allowing the attractive forces to dominate. When enough water is present, the strength of the diffuse double layer increases, thus the repulsive forces between particles becomes stronger than the attractive forces, resulting in the collapse of the aggregates, and the eventual formation of a homogenous mixture. An increase in water content also results in a decrease in capillary forces, allowing the aggregates to easily remould or collapse, thereby enabling the formation of a homogenous mixture. The submergence of the samples resulted in a smaller quantity of smaller sized pores, as seen by the shift in the MIP curves for both $30 \%$ and 50 $\%$ water content at $200 \mathrm{kPa}$ (Fig. 4(b)). Given that in a submerged state more water is present, the particles tend to rearrange themselves more so than in an unsubmerged state, contributing to the difference in MIP curves between the $30 \%$ and $50 \%$ samples at $200 \mathrm{kPa}$, and the submerged samples at $200 \mathrm{kPa}$ shown in Fig. 4(b).

The effects of compression on the microstructure of Kunigel-V1 can also be seen in the SEM and MIP results. An increase in pressure results in the collapse of the soil structure, resulting in the realignment of particles, the dissipation of air from the pores, and the movement of water into the micropores. The collapse of the soil structure which results in the realignment of the particles is seen by the decrease in size and number of voids in SEM images when the pressure is increased from $0.2 \mathrm{MPa}$ to 3 $\mathrm{MPa}$ at 30\% water content (Figs. 3(c) to (d)), and at 50\% water content (Figs. 3(e) to (f)). Additionally, the increase in pressure results in the formation of semibimodal curves centered at $0.5 \mu \mathrm{m}$ and $0.8 \mu \mathrm{m}$ for a water content of $30 \%$ and $3 \mathrm{MPa}$, and at $0.3 \mu \mathrm{m}$ and $0.5 \mu \mathrm{m}$ for a water content of $50 \%$ and $1.5 \mathrm{MPa}$, as shown in Fig. 4. Delage et al. (2006) stated that for compacted soils, a bimodal curve indicates the presence of an aggregate microstructure, with the modes showing the intra and inter-aggregate pore spaces. The presence of the semibimodal curves in this study suggested that the difference between the intra and inter-aggregate pore spaces was either not as large as expected or could not be observed for the specimens tested.

(2) NSF Clay

NSF Clay microstructure can be viewed from the SEM results presented in Fig. 5 and the MIP results presented in Fig. 6. Due to the properties of NSF Clay, samples at a natural water content turned to powder following CRS testing, thus SEM images were not able to be obtained at the same magnification as with other water contents, and as with Kunigel-V1. Subsequently, MIP samples at a natural water content also could not be obtained. At a natural water content, NSF Clay samples are not aggregated, as seen in the SEM image in Fig. 5(a), since they contain very little water $(0.2 \%-0.5 \%$, shown in Table 1). As with Kunigel-V1, the addition of water results in the formation of aggregates, seen with the difference in particle alignment and the creation of void spaces in Fig. 5(b) for NSF Clay at 30\% water content

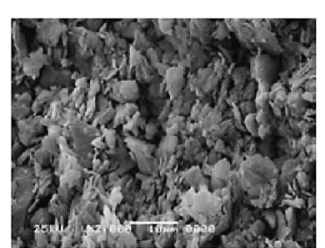

(a)

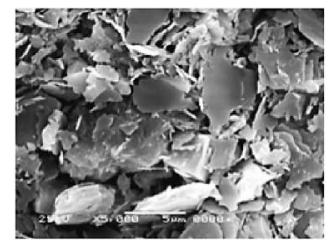

(b)

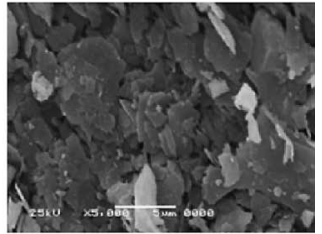

(c)

Fig. 5. SEM test results for NSF Clay. a) dry, $15 \mathrm{MPa}$, b) $30 \%, 1.5 \mathrm{MPa}$, and c) $50 \%, 1.5 \mathrm{MPa}$ 


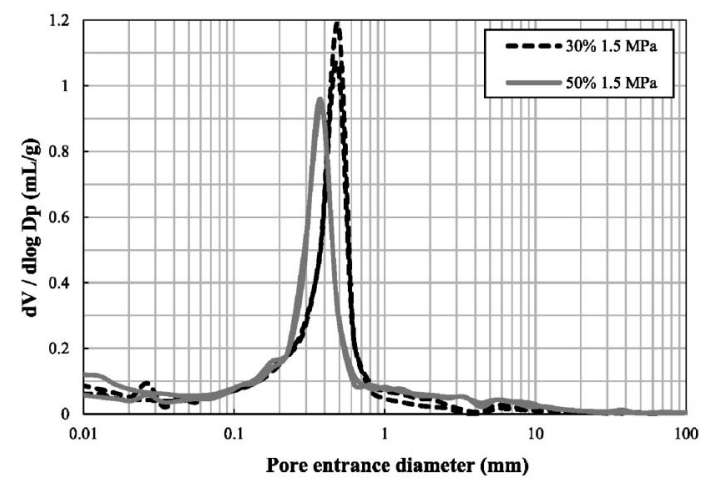

Fig. 6. MIP results for NSF Clay

and at a pressure of $1.5 \mathrm{MPa}$. Unlike Kunigel-V1 samples, water is not adsorbed between the particles, thus no swelling occurs. The repulsive forces due to the diffuse double layer are also stronger in NSF Clay than in Kunigel-V1 due to its non-swelling property, since no additional water is adsorbed between its layers, resulting in the collapse of the aggregates at a lower water content as the particles repel each other. This resulted in the formation of a homogenous paste-like mixture at $50 \%$ water content. Additionally, as more water is added, the capillary forces within the aggregates also decreases, enabling the formation of a homogenous mixture. This is noted by the increase in water content to $50 \%$ (Fig. 5(b)), which resulted in the collapse of the aggregates, the realignment of the particles, as well as a decrease in number and size of void spaces. MIP results support the above observations, where unimodal curves centered at $0.35 \mu \mathrm{m}$ and 0.5 $\mu \mathrm{m}$ for $50 \%$ and $30 \%$ water content, at $1.5 \mathrm{MPa}$, respectively, suggest the presence of similarly sized voids, which are smaller in size and total volume at higher water contents (Fig. 6). No other water contents or pressures have been tested to date. Visual observations of NSF Clay at $50 \%$ water content also showed the formation of a homogenous mixture.

\section{Compression Behaviour}

The CRS test results are provided in Figs. 7 and 8 for Kunigel-V1 and NSF Clay, respectively. As discussed above, an increase in water content results in the formation of aggregates, seen by the increase in the initial void ratio in Figs. 7 and 8 for Kunigel-V1 and NSF Clay, respectively. For NSF Clay, an increase in water content from $30 \%$ to $50 \%$ results in the collapse of aggregates, noted by the decrease in the initial water content in Fig. 8 below that of the natural sample. As stated before, at a natural water content, NSF Clay is relatively dispersed, producing voids filled with air, whereas at 50\% water content, the voids are mainly filled with water, with the particles spaced closer together due to their bonds to the water molecules, resulting in a smaller void ratio.

The change in degree of saturation $\left(S_{\mathrm{r}}\right)$ during compression was calculated for both Kunigel-V1 and NSF Clay, as shown in Figs. 9 and 10 respectively. For these calculations, it was assumed that the water was not

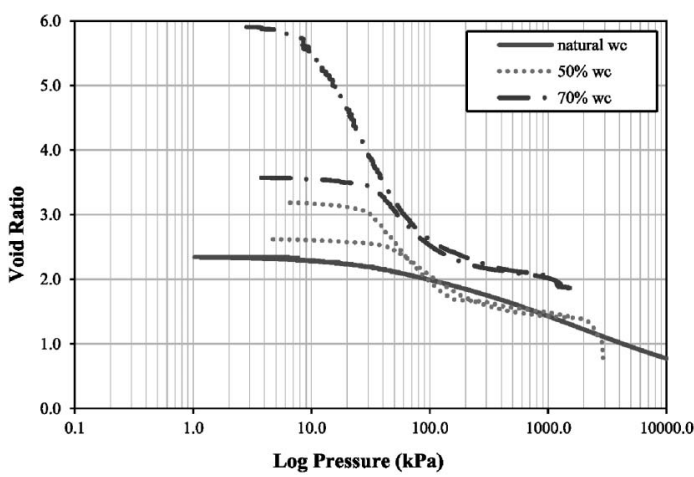

Fig. 7. $e-\log p$ graph for Kunigel-V1 CRS test results

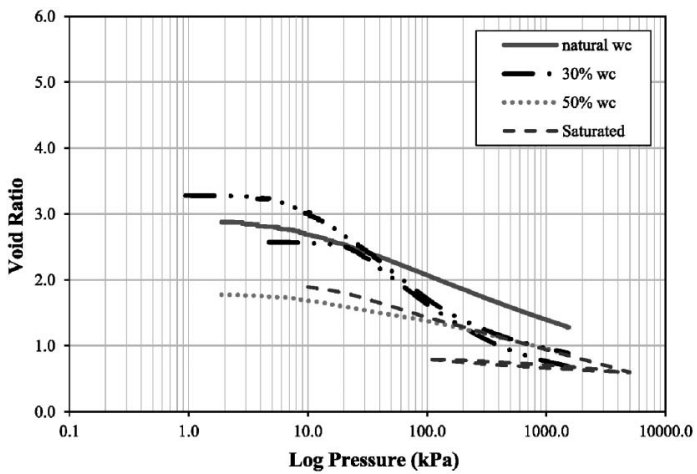

Fig. 8. $e-\log p$ graph for NSF Clay CRS test results

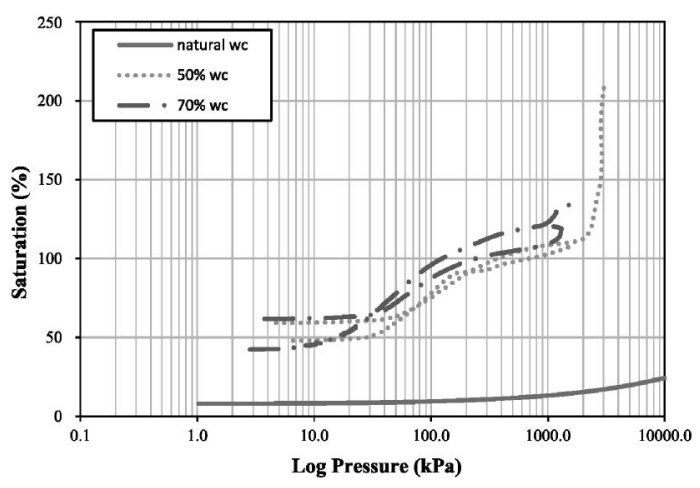

Fig. 9. Saturation curves for Kunigel-V1 CRS test results

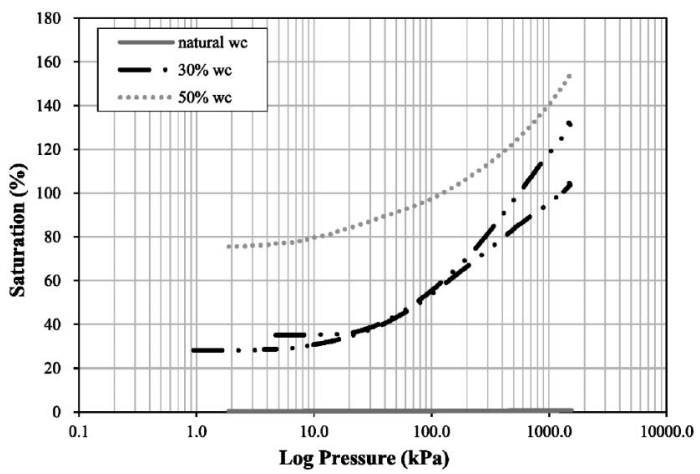

Fig. 10. Saturation curve for NSF Clay CRS test results 
drained, and thus the volume of water remained constant, with the decrease in void volume being a result of air dissipation. This assumption may be valid for Kunigel-VI, considering its low permeability values (on the order of $\sim 10^{-11}-10^{-12} \mathrm{~cm} / \mathrm{s}$ ). This was confirmed by visual observations, where no 'extra' water was observed on Kunigel-V1 samples, as well as a comparison of the water content measurement before and after CRS testing. Alternatively, NSF Clay has a much higher permeability, in the order of $\sim 10^{-6} \mathrm{~cm} / \mathrm{s}$, which allowed for water drainage to occur, which was confirmed by visual observations, where water accumulation on the samples was observed. Additionally, a comparison of the water content before and after CRS testing clearly showed a reduction in NSF Clay samples. Therefore, Fig. 10 does not show the precise $S_{\mathrm{r}}$ values for NSF clay except at initial conditions.

An increase in pressure results in the collapse of the soil structure, the dissipation of air from the pores, and the movement of water into the micropores. This in turn results in a decrease in the void ratio (Fig. 7), and an increase in the degree of saturation $\left(S_{\mathrm{r}}\right)$ (Fig. 9), where the lower degree of saturation corresponds to the higher initial void ratio. The initial application of pressure causes the dissipation of air from the macro-voids, and a movement of the water into the micro-voids, resulting in the collapse of the macro-structures at a large compression index $\left(C_{\mathrm{c}}\right)$. At higher water contents, the slope of the $e-$ $\log p$ curve, or $C_{\mathrm{c}}$, is higher, given the dissipation of air from the macro-pores (resulting in the decrease in void ratio) occurs at a higher rate than at water contents where the macro-pores are smaller, or non-existent. Beyond about $150 \mathrm{kPa}$, the curve levels off, signifying a collapse of the structures. In turn, a further increase in pressure causes the dissipation of air from the micro-voids resulting in the crushing of the aggregates until such point that only water exists in the voids. Upon collapse, the sample cannot be further compressed, as most of the air has dissipated and mainly water exists, as seen by the $100 \% S_{\mathrm{r}}$ values shown in Fig. 9.

By definition, saturation, $\left(S_{\mathrm{r}}\right)$ should not exceed $100 \%$. However, at $70 \%$ water content, $S_{\mathrm{r}}$ exceeded $100 \%$ at pressures greater than $100 \mathrm{kPa}$, and at $50 \%$ water content, the same trend was observed for pressures greater than $150 \mathrm{kPa}$. This can be attributed to an error in the measurement of the water content, the initial volume and/or the weight of the specimen at the initial conditions. Indeed, as Kochmanová and Tanaka (2009) have indicated from the observation of X-ray Computed Tomography (X-ray CT) scans, unsaturated Kunigel-V1 samples are not homogeneous, and contain pockets of less dense areas, thought to be aggregates, throughout samples. For Kunigel-V1 samples, nearly 100\% saturation, not over $100 \%$, is reached at approximately $150 \mathrm{kPa}$ for the $50 \%$ and $70 \%$ water content samples, as seen in Fig. 9. In this state, the macro-voids are filled with water, and the excess water begins to move into the micro-voids, or the intra-aggregate voids. At this point the $C_{\mathrm{c}}$ decreases and although some air may be trapped in isolat-

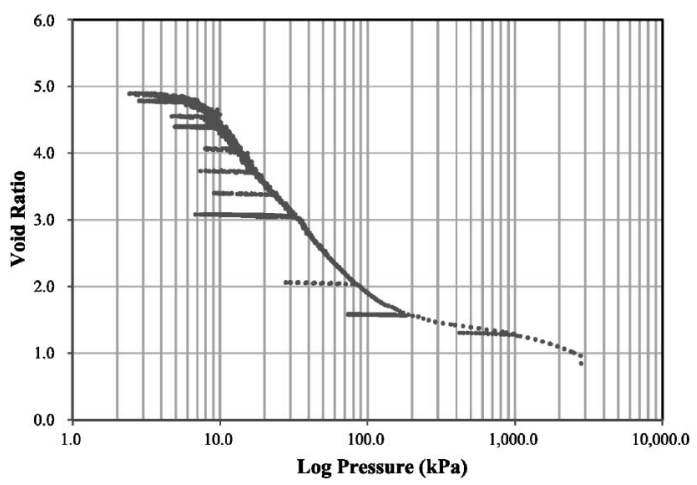

Fig. 11. Cyclic CRS test results for $50 \%$ water content Kunigel-V1 sample

ed micro-voids, further compression results in sample extrusion from the cell. This behaviour is observed in the $e$ $-\log p$ relation of Fig. 7 as a sharp decrease in void ratio and in $S_{\mathrm{r}}$ of Fig. 9 as $S_{\mathrm{r}}$ exceeds $100 \%$.

A sample at $50 \%$ water content was loaded, unloaded and reloaded at various pressures, and the results are shown in Figs. 11 to 13 . It was believed that at low pressures the swelling $\left(C_{\mathrm{s}}\right)$, and recompression $\left(C_{\mathrm{r}}\right)$ indexes would be very small compared with $C_{\mathrm{c}}$ of the virgin loading, as the void ratio would remain constant when unloaded and reloaded, since the arrangement of soil particles would not rebound appreciably. As the pressure increases, the void ratio decreases and the $S_{\mathrm{r}}$ increases. Subsequently, water is extruded from the aggregates, and more of the voids are filled with water rather than air, as the degree of saturation increases. It is thought that this extra water results in the formation of thicker diffuse double layers, resulting in the repulsion of particles and an increase in swelling capability. Thus, it is expected that with an increase in pressure, $C_{\mathrm{r}}$ would become large. Indeed Börgesson et al. (1990) showed the $C_{\mathrm{s}} / C_{\mathrm{c}}$ ratio for partially saturated smectite to be 0.1 , but it increased to as much as 0.72 for saturated smectite. Their test results show that an increase in saturation results in an increase in swelling, thus an increase in pressure should also result in an increase in $C_{\mathrm{s}}$ and $C_{\mathrm{r}}$ values.

The test results shown in Fig. 11, where the strain rate was $0.0034 \mathrm{~mm} / \mathrm{min}$ for the virgin loading and the unloading-reloading curves at lower pressures, and 0.00004 $\mathrm{mm} / \mathrm{min}$, a strain rate low enough to allow for swelling, for the unloading-reloading curves at higher pressures, clearly show that the unload-reload curve remains nearly horizontal, and that $C_{\mathrm{r}}$ remained nearly equal for all unload-reload curves, and did not increase significantly with an increase in pressure. However, as shown in Fig. 12, $100 \%$ saturation was achieved at a pressure of $730 \mathrm{kPa}$. Therefore, although enough water exists, no swelling of the aggregates was observed. Figure 13 shows the compression and recompression results based on the interval numbers, showing that the $C_{\mathrm{c}}$ changes with an increase in pressure (corresponding to an increase in the interval number), while $C_{\mathrm{s}}$ and $C_{\mathrm{r}}$ remain virtually unchanged, further confirming that no swelling occurred. 


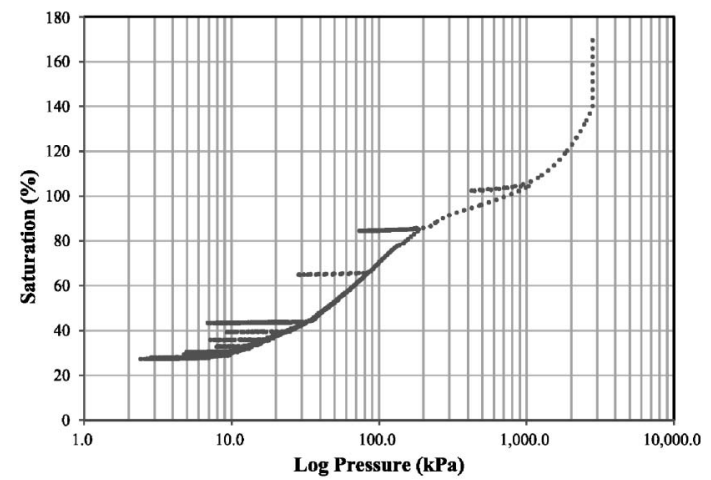

Fig. 12. Saturation curve for cyclic CRS test results for $50 \%$ water content Kunigel-V1 sample

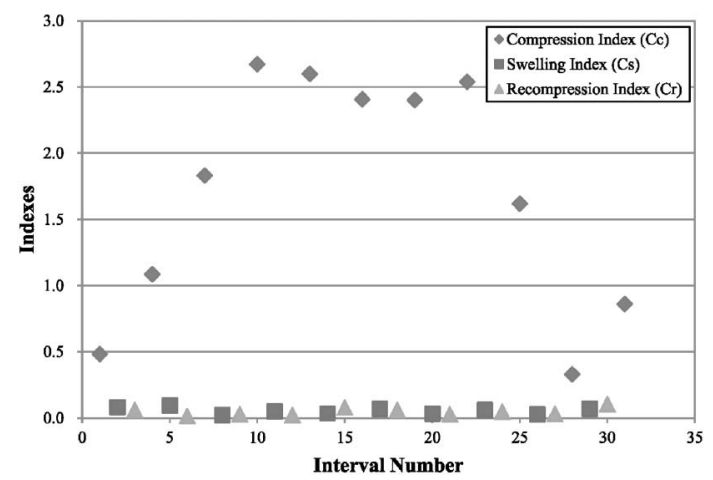

Fig. 13. Cyclic CRS test results for $50 \%$ water content Kunigel-V1 sample

Two possible explanations may be presented for the phenomenon mentioned above; one regarding the soil fabric and the other regarding time. For example, for cyclic testing, it was shown that $100 \%$ saturation was achieved at a pressure of $730 \mathrm{kPa}$. At such high pressures, it is believed that although enough water exists around the particles, the pressure is too high to allow them to swell/expand freely. This explanation will be further discussed in the next section. Another explanation is that the low permeability of Kunigel-V1 means not enough time exists for the water to move through the clay. There is a possibility that the strain rate employed in this investigation is not slow enough for water to move from one location to another, allowing for particle rearrangement. Komine and Ogata $(1994,2004)$ and Komine et al. (2009) have performed numerous studies to observe the swelling behaviour of Kunigel-V1. The testing methods employed required a testing period of one week, but swelling was observed within the first day, meaning swelling was almost instantaneous. From their test results, it was concluded that the strain rate used for the CRS testing in this study was slow enough to allow the clay particles to swell assuming they were in parallel arrangement and had formed the diffuse double layer. Thus, it is the soil fabric that seems to influence the swelling behaviour of KunigelV1.
Table 2. CVDS summary for unsaturated Kunigel-V1 samples

\begin{tabular}{ccclcl}
\hline $\begin{array}{c}\text { Water } \\
\text { content }\end{array}$ & $\begin{array}{c}\text { Pressure } \\
(\mathrm{kPa})\end{array}$ & $\begin{array}{c}\sigma(\mathrm{kPa}) \text { at } \\
\tau_{\max }\end{array}$ & $\begin{array}{c}\tau_{\max } \\
(\mathrm{kPa})\end{array}$ & $\tau_{\max } / \mathrm{P}$ & $\varphi$ \\
\hline \multirow{2}{*}{ natural } & 50 & 17.82 & 13.4 & 0.27 & \\
& 100 & 53.13 & 24.92 & 0.25 & \\
$30 \%$ & 200 & 110.3 & 51.42 & 0.26 & \\
& 50 & 31.51 & 33.5 & 0.67 & \\
& 100 & 55.09 & 45.14 & 0.45 & 40.4 \\
$50 \%$ & 200 & 104.72 & 67.56 & 0.34 & \\
& 50 & 35.92 & 34.88 & 0.70 & \\
& 100 & 57.24 & 54.65 & 0.55 & \\
& 200 & 114.28 & 96.85 & 0.48 & \\
\hline
\end{tabular}

Table 3. CVDS summary for submerged Kunigl-V1 samples

\begin{tabular}{cccccc}
\hline $\begin{array}{c}\text { Water } \\
\text { content }\end{array}$ & $\begin{array}{c}\text { Pressure } \\
(\mathrm{kPa})\end{array}$ & $\begin{array}{c}\sigma(\mathrm{kPa}) \text { at } \\
\tau_{\max }\end{array}$ & $\begin{array}{c}\tau_{\max } \\
(\mathrm{kPa})\end{array}$ & $\tau_{\max } / \mathrm{P}$ & $\varphi$ \\
\hline natural & 100 & 89.51 & 28.75 & 0.29 & 20.4 \\
$50 \%$ & 50 & 47.23 & 19.1 & 0.38 & \\
\hline
\end{tabular}

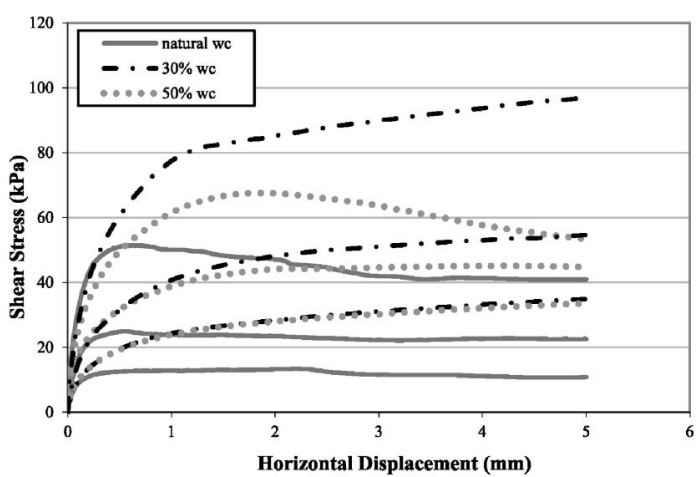

Fig. 14. CVDS shear strength results for unsaturated Kunigel-V1

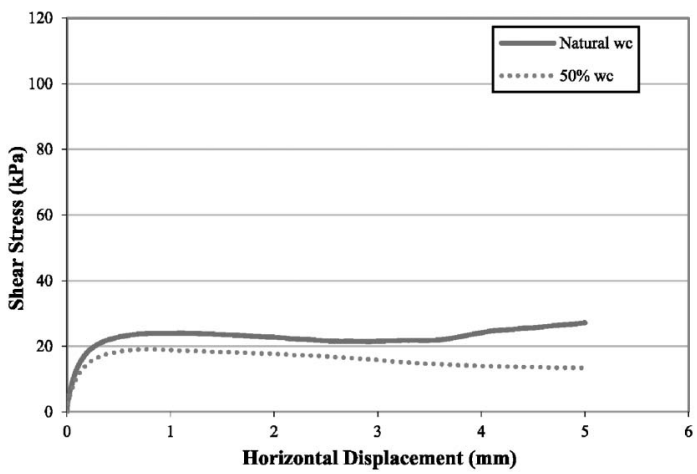

Fig. 15. CVDS shear strength results for submerged Kunigel-V1

\section{Shearing Behaviour}

Tables 2 and 3 show the test conditions and main test results from the CVDS testing for Kunigel-V1 of unsaturated and submerged samples, respectively. Figures 14 and 15 show the displacement-shear stress relationship for unsaturated and submerged Kunigel-V1 samples, respectively. Two submerged samples were tested, one at an initial natural water content, and the other at an initial 
water content of $50 \%$. The natural water content sample was tested at $100 \mathrm{kPa}$, while the $50 \%$ water content sample was tested at $50 \mathrm{kPa}$. Under constant vertical pressure, the samples were submerged and swelling was observed for several weeks.

Figures 14 and 15 show the displacement-shear stress relationship for unsaturated and submerged Kunigel-V1 samples, respectively. Both results show that an increase in the vertical confining pressure results in an increase in shear strength. The relationship between the shear stress and the displacement varied with sample conditions. For example, samples at a natural water content show clear peak strengths but the shear strength in samples at 30\% water content increases with displacement and no peak strength was noted by the $5 \mathrm{~mm}$ displacement mark. In this paper, the peak strength, whether clearly shown, or the strength at $5 \mathrm{~mm}$ displacement is defined as the undrained shear strength $\left(S_{\mathrm{u}}\right)$. Although the samples in this study are not saturated, the $S_{\mathrm{u}}$ terminology was used since testing was carried out under constant volume conditions.

Figure 16 shows the $S_{\mathrm{u}}$ values plotted against the vertical pressure applied $(p)$ prior to shearing. This figure shows that the slope corresponding to the undrained shear strength incremental ratio $\left(S_{\mathrm{u}} / p\right)$ is constant for samples at all water contents, and $S_{\mathrm{u}}$ can be presented by the following equation:

$$
S_{\mathrm{u}}=\left(S_{\mathrm{u}} / p\right) p+C_{\mathrm{e}}
$$

where $C_{\mathrm{e}}$ is the intercept at $p=0$, and may correspond to apparent cohesion.

The relation of $S_{\mathrm{u}}$ and $p$ for natural water content samples goes through the origin, i.e. $C_{\mathrm{e}}=0$, which is the same as in normally consolidated saturated clay. In addition, the $S_{\mathrm{u}} / p$ ratio is about 0.25 , which is very close to the $S_{\mathrm{u}} /$ $p$ ratio for saturated normally consolidated clays. The $S_{\mathrm{u}} /$ $p$ ratio remains almost constant with an increase in water content to $30 \%$; the $C_{\mathrm{e}}$ however, increases significantly. A further increase in water content to $50 \%$ results in a slight increase in the $S_{\mathrm{u}} / p$ ratio but a decrease in $C_{\mathrm{e}}$. These results can be explained due to the presence of capillary forces, or in other words, matric suction. An increase in water content from natural to $30 \%$ results in an increase in capillary forces and thus matric suction, resulting in an increase in $C_{\mathrm{e}}$. A further increase in water content, or the submergence of the samples, causes the disappearance of the capillary forces, thus the $C_{\mathrm{e}}$ decreases, and the slope resembles that of the natural sample, seen by the two submerged samples in Fig. 16. Therefore, it seems that the influence of water content on the undrained behaviour of unsaturated samples can be explained by the magnitude of the matric suction; however, suction is not a complete explanation.

Figure 17 shows the stress paths and failure envelopes of the unsaturated Kunnigel-V1 samples tested. Although $S_{\mathrm{u}}$ varies depending on the water content, the friction angle $(\varphi)$ is constant at $40.4^{\circ}$ for every specimen (also shown in Table 2). At a natural water content, the clay samples are in powder form, thus, aggregates are non-existent, or

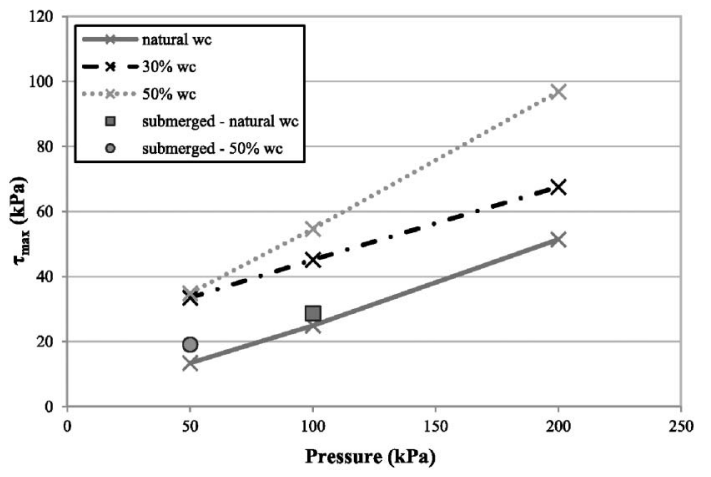

Fig. 16. Maximum shear strength for Kunigel-V1 samples

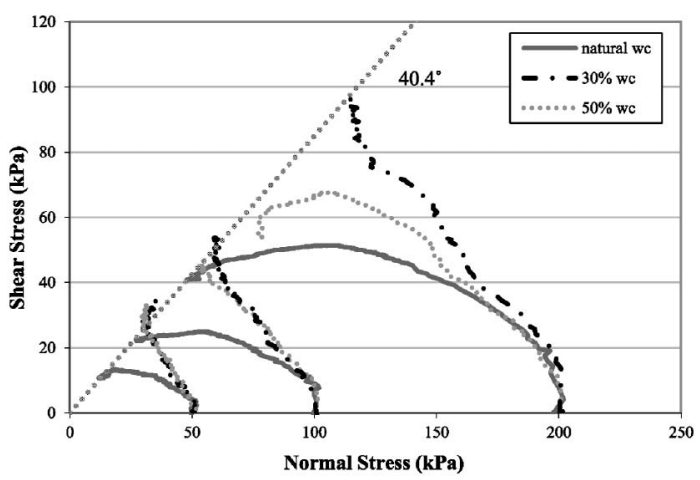

Fig. 17. CVDS stress path results for unsaturated Kunigel-V1

very small in size, as described above. In conventional soil mechanics, this would correspond to a very loose sand sample. When sheared under constant volume, a decrease in the vertical stress, shown by the negative dilatancy, is observed, as seen in Fig. 17 for Kunigel-V1. The addition of water causes aggregates to form and surround the water molecules. The formation of the aggregates does not affect the failure development in the clays, seen by the constant friction angle for Kunigel-V1 samples in Fig. 17; instead, the addition of water affects the dilatancy of the clays, seen by the change in shape of the stress paths. Aggregates formed at a certain water content, 30\% in this case, are strong, and when sheared, they do not collapse easily. In another words, the dilatancy behaviour tends to be positive, such that the stress path moves up vertically to the failure envelope. Therefore, the undrained shear strength increases, and some apparent cohesion is present. A further increase in water content to $50 \%$ results in the formation of larger aggregates, but a decrease in the stiffness of the aggregates, seen by the ease of remoulding. When sheared, the aggregates are easily broken due to the decrease in capillary forces, resulting in a decrease in $S_{\mathrm{u}}$ especially under large vertical pressures, as seen in Fig. 17.

However, a further increase in water content, in the form of submergence, results in completely different behaviour. Figure 18 shows the stress paths and failure envelopes for the submerged samples tested. The angle of friction obtained for the submerged samples was $20.4^{\circ}$, 


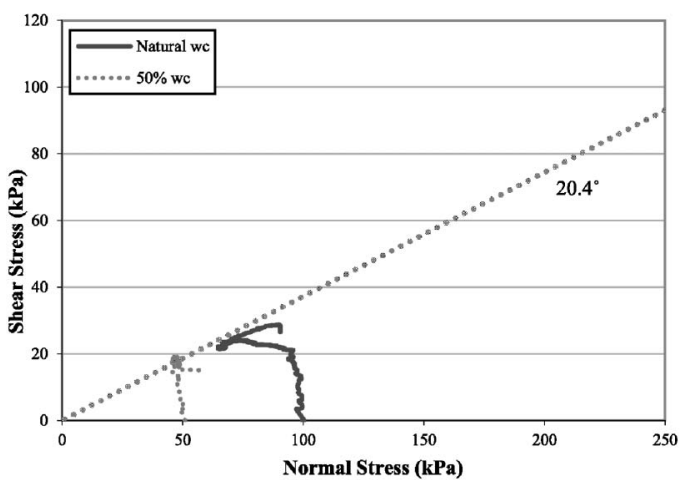

Fig. 18. CVDS shear path results for submerged Kunigel-V1

as shown in Table 3. As samples become increasingly saturated, the friction between the particles decreases due to the effects of the diffuse double layer, which acts as a lubricant between particles. It is well known that the friction angle of saturated smectite is very small, a property which occasionally causes large scale landslides to occur. Figure 17 indicates that a change in water content has little effect on the friction angle of unsaturated Kunigel-V1 for the range of water contents tested. However, at a water content of $50 \%$ and a confining pressure of 200 $\mathrm{kPa}$, where the degree of saturation was close to $100 \%$, as seen in Fig. 9, it is apparent that the friction angle begins to decrease, but is clearly greater than the failure envelope of the submerged samples, as seen in Fig. 18. This result seems to be consistent with results from the cyclic CRS testing, which showed that even when the sample was near saturation due to compression, the $C_{\mathrm{r}}$ was much smaller than the $C_{\mathrm{c}}$.

Blatz et al. (2002) compared the SWCC of sand-bentonite mixtures at different water contents, and found that those samples with lower water contents produced higher matric suction values. They attributed this to the differences in microstructure due to the initial water content. Although this would account for the difference in shear strengths, it does not account for the change in friction angles due to saturation. However, the difference in friction angles between the unsaturated and saturated samples suggests that the friction angle is affected by the degree of saturation, and thus the existence of the diffuse double layer surrounding the clay particles is of importance. Table 4 and Figs. 19 to 22 show the CVDS test results for NSF Clay samples. The results from Table 4 and Figs. 19 and 20 show similar results to Kungel-V1, where an increase in water content from a natural water content to $30 \%$ resulted in an increase in shear strength for all vertical confining pressures. However, for NSF Clay, a further increase in water content to $50 \%$ resulted in a lower shear strength than that observed for the sample with a water content of $30 \%$. This corresponds to the submerged Kunigel-V1 samples, where a decrease in shear strength was observed. The displacement-shear stress relationship in Fig. 19 shows similar results as those obtained for Kunigel-V1, where for natural water content samples the peak shear strength was obtained at a small
Table 4. CVDS summary for NSF Clay

\begin{tabular}{crrllll}
\hline $\begin{array}{c}\text { Water } \\
\text { content }\end{array}$ & $\begin{array}{c}\text { Pressure } \\
(\mathrm{kPa})\end{array}$ & $\begin{array}{c}\sigma(\mathrm{kPa}) \text { at } \\
\tau_{\max }\end{array}$ & $\begin{array}{c}\tau_{\max } \\
(\mathrm{kPa})\end{array}$ & $\tau_{\max } / \mathrm{P}$ & $\varphi$ & $\mathrm{c}$ \\
\hline \multirow{5}{*}{ natural } & 50 & 16.51 & 15.7 & 0.314 & & \\
& 100 & 47.26 & 29.68 & 0.2968 & 41.1 & 10.9 \\
& 200 & 87.78 & 51.35 & 0.25675 & & \\
$30 \%$ & 50 & 35.53 & 49.27 & 0.9854 & & \\
& 100 & 56.11 & 67.62 & 0.6762 & 44.1 & 14.3 \\
& 200 & 72.28 & 85.05 & 0.42525 & & \\
$50 \%$ & 50 & 19.37 & 18.59 & 0.3718 & & \\
& 100 & 43.99 & 35.98 & 0.3598 & 34.6 & 5.4 \\
Saturated & 200 & 87.31 & 61.92 & 0.3096 & & \\
& 100 & 35.65 & 50.98 & 0.3565 & 32.3 & - \\
\hline
\end{tabular}

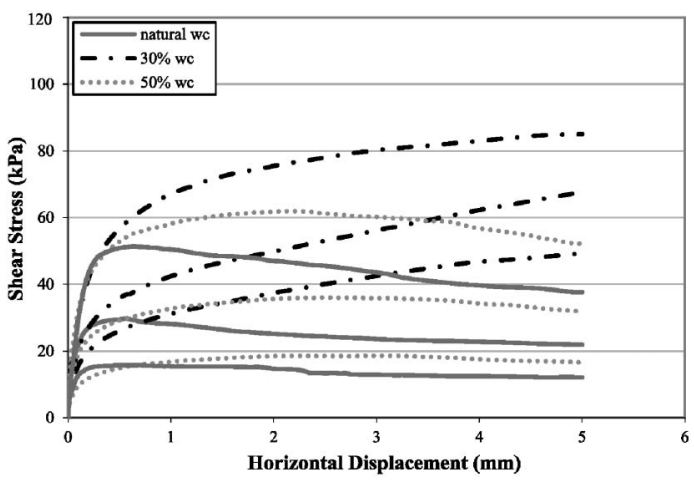

Fig. 19. CVDS shear strength results for NSF Clay

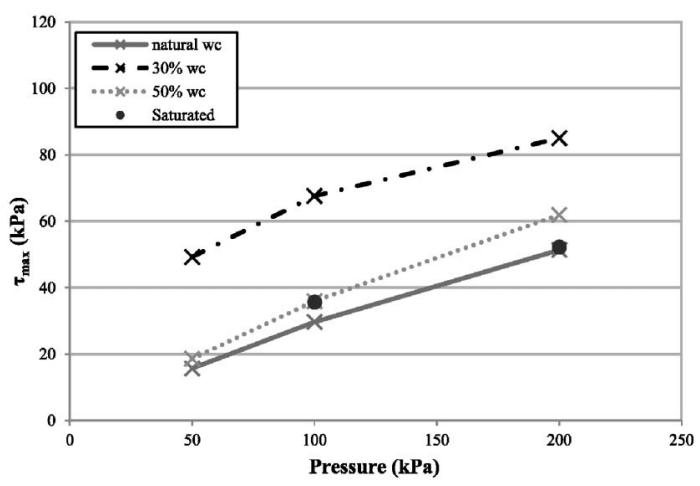

Fig. 20. Maximum shear strength for NSF Clay samples

displacement (less than $1 \mathrm{~mm}$ ), and $30 \%$ water content samples displayed no peak shear strength as the shear strength continued to increase past a displacement of 5 mm. Unlike Kunigel-V1, all 50\% water content samples displayed peak shear strengths at relatively large displacements, ranging from $2.2 \mathrm{~mm}$ to $3.2 \mathrm{~mm}$.

For NSF Clay, at a natural water content the $S_{\mathrm{u}}-p$ relation also goes through the origin, i.e. $C_{\mathrm{e}}=0$, and $S_{\mathrm{u}} / p$ ratio is the same as that for Kunigel-V1, 0.25. An increase in water content to $30 \%$ results in an almost constant $S_{\mathrm{u}} /$ $p$ ratio, and an increase in $C_{\mathrm{e}}$. However, the increase in $C_{\mathrm{e}}$ observed is almost double that observed in Kunigel-V1. The difference can be explained by the adsorption of water by Kunigel-V1, which causes the capillary forces, 


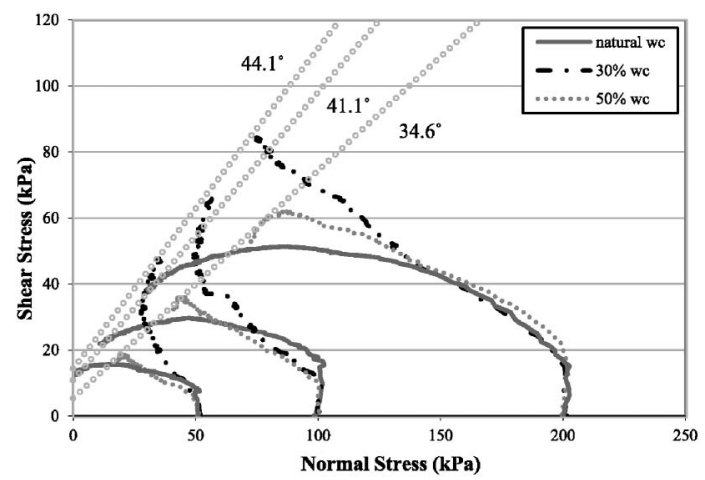

Fig. 21. CVDS stress path results for unsaturated NSF Clay

or the matric suction within the Kunigel-V1 to not be as strong as that observed in NSF Clay. Rao and Revanasiddappa (2005) showed that remoulded clays formed smaller structures, causing a decrease in the pore entrance diameter, which resulted in an increase in the matric suction. The voids within the NSF Clay samples at 30\% water content are smaller in size and volume than the $30 \%$ water content Kunigel-V1 samples, as was discussed above, resulting in higher matric suction. Unlike Kunigel$\mathrm{V} 1$, a further increase in water content to $50 \%$ resulted in no change in the $S_{\mathrm{u}} / p$ ratio and a decrease in $C_{\mathrm{e}}$, so that the $S_{u}-p$ relation also goes through the origin, much like the natural water content samples. Figure 20 shows the $S_{u}$ $-p$ relation for fully saturated NSF Clay. The saturated NSF Clay sample was preconsolidated prior to testing in order to obtain a fully saturated sample. Similarly to Kunigel-V1, the $S_{\mathrm{u}}$ values for the saturated samples are similar to those obtained at a natural water content.

Figure 21 shows the stress paths and failure envelopes of the unsaturated NSF Clay samples tested. The angle of friction $(\varphi)$ exceeded $40^{\circ}$ for natural and $30 \%$ water content samples, slightly higher than the $40.4^{\circ}$ obtained for Kunigel-V1. The cohesion $(c)$ was also observed, with values of $10.9 \mathrm{kPa}, 14.3 \mathrm{kPa}$, and $5.4 \mathrm{kPa}$ at a natural, $30 \%$ and $50 \%$ water contents, respectively (Table 4 ). Similar to Kunigel-V1, the angle of friction of NSF Clay samples does not change greatly with a change in water content in unsaturated conditions, as an increase in water content from natural to $30 \%$ results in an increase in the angle of friction of only $3.0^{\circ}$. This signifies that in powder clays, the angle of friction is not greatly affected by the water content. A further increase to $50 \%$ water content results in a $9.5^{\circ}$ decrease in friction angle. As stated above, at $50 \%$ water content NSF Clay are homogenous, and are believed to be at or near saturation, causing a reduction in the friction angle. A friction angle of $32.3^{\circ}$ (Fig. 22) was obtained for the saturated sample, a value that is typically measured in saturated clays, and much higher than the $20.4^{\circ}$ obtained for the submerged Kunigel-V1 samples.

It should be pointed out that NSF Clay does not contain any swelling materials that would result in the significant reduction in $\varphi$. Therefore, it can be said that the behaviour of unsaturated soils containing fine materials

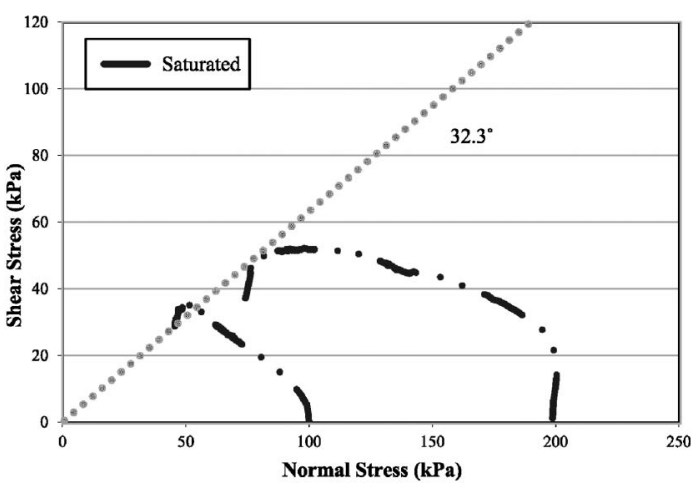

Fig. 22. CVDS stress path results for saturated NSF Clay

cannot be interpreted solely by matric suction.

\section{CONCLUSION}

The influence of the soil fabric on the mechanical properties of Kunigel-V1 and NSF Clay were observed in this study through various laboratory tests. The soil fabric formation was observed with SEM and MIP testing, which showed that an increase in water content resulted in the formation of aggregates in both clays. At higher water contents, however, NSF Clay began to form a homogenous paste-like mixture, while Kunigel-V1 was still aggregated; this was attributed to Kunigel-V1's unique ability to adsorb water and swell. CRS testing showed that an increase in pressure results in the dissipation of air and movement of water from the macro-voids to the micro-voids. Due to the low permeability of Kunigel-V1, drainage did not occur during testing, resulting in sample extrusion at higher pressures as samples could not be compressed further. The formation of aggregates, through an increase in water content in unsaturated samples, resulted in an increase in the undrained shear strength due to a change in dilatancy, but had no influence on the friction angle. It is believed that the stiffness of the aggregates increases due to large matric suctions, resulting in behaviour that is similar to compacted dense granular material. At high water contents, aggregates are easily broken down, resulting in contractive behaviour during shearing and a decrease in strength. The submergence and saturation of Kunigel-V1 results in a lubricating effect on the particles, thus decreasing the shear strength as the friction between particles decreases.

\section{ACKNOWLEDGEMENTS}

The authors would like to thank the Port and Airport Research Institute and their staff for their assistance and use of the Mercury Intrusion Porosimeter and the Scanning Electron Microscope used in this study.

\section{REFERENCES}

1) Alonso, E. E., Gens, A. and Josa, A. (1990): A constitutive model for partially saturated soils, Géotechnique, 40(30), 405-430. 
2) Blatz, J. A., Graham, J. and Chandler, N. A. (2002): Influence of suction on the strength and stiffness of compacted sand-bentonite, Canadian Geotechnical Journal, 39, 1005-1015.

3) Börgesson, L., Broc, D. and Plas., F. (1990): Mechanical properties of dense Ca-smectite clay, Engineering Geology, 28, 419-429.

4) Delage, P., Marcial, D., Cui, Y. J. and Ruiz, X. (2006): Ageing effects in a compacted bentonite: a microstructure approach, Géotechnique, 56(5), 291-304.

5) Gens, A. and Alonso, E. E. (1992): A framework for the behaviour of unsaturated expansive clays, Canadian Geotechnical Journal, 29, 1013-1032.

6) Hanzawa, H., Nutt, N., Lunne, T., Tang, Y. X. and Long, M. (2007): A comparative study between the NGI direct simple shear apparatus and the Mikasa direct shear apparatus, Soils and Foundations, 47(1), 47-58.

7) Kochmanová, N. and Tanaka, H. (2009): Bentonite microstructure formation in clay liners, The 24th International Conference on Solid Waste Technology and Management Conference Proceedings, Philadelphia, U.S.A., 64-75.
8) Komine, H. (2004): Simplified evaluation for swelling characteristics of bentonites, Engineering Geology, 71, 265-279.

9) Komine, H. and Ogata, N. (1994): Experimental study on swelling characteristics of compacted bentonite, Canadian Geotechnical Journal, 31, 478-490.

10) Komine, H. and Ogata, N. (2004): Predicting swelling characterstics of bentonites, Journal of Geotechnical and Geoenvironmental Engineering, ASCE, 130(8), 818-829.

11) Komine, H., Yasuhara, K. and Murakami, S. (2009): Swelling characteristics of bentonites in artificial seawater, Canadian Geotechnical Journal, 46, 177-189.

12) Marcial, D., Delage, P. and Cui, Y. J. (2002): On the high stress compression of bentonites, Canadian Geotechnical Journal, 39, 812-820.

13) Rao, S. M. and Revanasiddappa, K. (2005): Role of microfabric in matrix suction of residual soils, Engineering Geology, 80(1-2), 60-70.

14) Takada, N. (1993): Mikasa's direct shear apparatus, test procedures and results, Geotechnical Testing Journal, 16(3), 314-322. 